\title{
A Study of Modeling Techniques of Building Energy Consumption
}

\author{
Abdellah Zerroug \\ Electrical Engineering Department \\ Ferhat Abbas Setif-1 University \\ Setif, Algeria \\ abzerroug@gmail.com
}

\author{
Egils Dzelzitis \\ Institute of Heat, Gas and Water Technology \\ Riga Technical University \\ Riga, Latvia \\ egils@lafipa.lv
}

\begin{abstract}
Residential energy consumption accounts for more than $40 \%$ of the total energy consumed in the world. The residential sector is the biggest consumer of energy in every country, and therefore focusing on the reduction of energy consumption in this sector is very important. The energy consumption characteristics of the residential sector are very complicated and the variables affecting the consumption are wide and interconnected, so more detailed models are needed to assess the impact of adopting efficient and renewable energy technologies suitable for residential applications. The aim of this paper is to review some of the techniques used to model residential energy consumption. They are gathered in two categories: top-down and bottom-up. The top-down approach considers the residential sector as an energy sink and does not take into account the individual end-uses. The bottom-up approach uses the estimated energy consumption of a representative set of individual houses and extrapolates it to regional and national levels. Based on the strengths, shortcomings, and purposes, an analytical review of each technique, is provided along with a review of models reported in the literature.
\end{abstract}

Keywords-energy consumption; modeling techniques; residential sector; top-down; bottom-up; $\mathrm{CO}_{2}$ emissions

\section{INTRODUCTION}

Residential Building Energy Consumption (RBEC) is defined as the energy consumed by households excluding transportation uses. In the residential sector, energy is used for equipment and to provide heating, cooling, and lighting. It is affected by income, energy prices, building location, household characteristics, weather, type and efficiency of equipment, energy access, availability, and energy related policies. As a result, the type and amount of energy can vary widely within and across regions and countries [1]. In recent years, although measurements and policies have been taken to reduce energy consumption and gas emissions, and the residential buildings have continuously improved in efficiency, substantial differences in the residential energy consumption are still being observed in similar dwellings [2-4]. Globally, residential energy consumption represents the $16-50 \%$ of the total and averages approximately at $30 \%$ as shown in Figure 1 [5]. Only $10 \%$ of the population of the world exploits $90 \%$ of fossil fuel resources. Today's energy systems rely heavily on fossil fuel resources making them diminish ever faster. The world must prepare for a future without fossil fuels. Sustainable energy consumption has become an urgent matter for all countries. World residential delivered energy consumption will increase by $57 \%$ from 2010 to 2040 (Table I) [1].

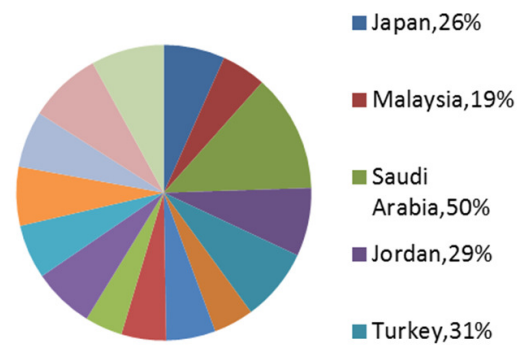

Fig. 1. Residential energy consumption shown as a percentage of national energy consumption and in relative international form [1]

In Europe the built environment consumes $40 \%$ of the produced energy. A large part of this energy is consumed in residential buildings. Households account for about $30 \%$ of the total building-related energy consumption in OECD countries [6]. A $30-57 \%$ of the energy consumed by households is spent on space and domestic water heating, making conservation in this area a matter of vital importance [2]. This significant consumption level indicates the crucial role that the residential sector plays in total energy consumption, which means that it is necessary to understand the characteristics associated to energy consumption to better prepare for the increasing energy demand in the future. In response to climate change, high energy prices, and energy supply/demand, there is an interest in understanding the detailed consumption characteristics of the residential sector in an effort to promote conservation, efficiency, technology implementation, and energy source switching, such as to on-site renewable energy[1].

Other sectors such as commercial, agriculture, transport and industry have a regular energy consumption because usually these sectors are private or under centralized ownership and they are well defined and regulated. The energy consumption in the residential sector is very complex because of the large variety of construction types, sizes, thermal envelope materials, and the very wide variety of occupant behavior. 
TABLE I. GLOBAL RESIDENTIAL DELIVERED ENERGY CONSUMPTION

\begin{tabular}{|c|c|c|c|c|c|c|c|c|}
\hline Region & $\mathbf{2 0 1 0}$ & $\mathbf{2 0 1 5}$ & $\mathbf{2 0 2 0}$ & $\mathbf{2 0 2 5}$ & $\mathbf{2 0 3 0}$ & $\mathbf{2 0 3 5}$ & $\mathbf{2 0 4 0}$ & Average annual percent change 2010-2040 \\
\hline OECD & 28.2 & 28.1 & 29 & 29.9 & 30.8 & 31.3 & 32 & 0.4 \\
\hline Americas & 13.2 & 12.8 & 12.9 & 13.2 & 13.5 & 13.9 & 14.2 & 0.3 \\
\hline Europe & 11.7 & 11.9 & 12.5 & 13.1 & 13.5 & 13.7 & 13.9 & 0.6 \\
\hline Asia & 3.3 & 3.4 & 3.5 & 3.7 & 3.8 & 3.8 & 3.9 & 0.5 \\
\hline Non OECD & 23.9 & 27 & 30.8 & 35.1 & 40.0 & 45.0 & 49.8 & 2.5 \\
\hline Europe and Eurasia & 6.3 & 6.3 & 6.7 & 7.1 & 7.7 & 8.1 & 8.6 & 1.0 \\
\hline Asia & 10.6 & 12.8 & 15.6 & 18.7 & 22.2 & 25.9 & 29.6 & 3.5 \\
\hline Middle East & 3.4 & 3.9 & 4.2 & 4.4 & 4.6 & 4.7 & 4.8 & 1.2 \\
\hline Africa & 1.6 & 1.7 & 1.9 & 2.2 & 2.5 & 2.8 & 3.2 & 2.4 \\
\hline Central and S. America & 2.0 & 2.3 & 2.4 & 2.7 & 3.0 & 3.4 & 3.7 & \\
\hline World & 52.0 & 55.1 & 59.8 & 65.0 & 70.8 & 76.3 & 81.8 & \\
\hline
\end{tabular}

Space heating and cooling, domestic hot water, appliances, and lighting are the major utilities that consume most energy in residential buildings. Total Residential Energy Consumption (REC) is defined as the energy required by the aggregates, including the losses due to energy transmission or appliances efficiencies. The energy consumed for heating and cooling space has the biggest share of the total REC. This energy can be supplied by different sources including passive solar gain, occupants gain, lighting and appliances gain. The total REC for a given area or a country gives the regional or national residential sector consumption.

The mean object of the building energy consumption modeling is to quantify the energy needs and requirements as a function of input parameters. The most common reason for using models is to determine the energy supply requirements at a large scale, and the change in energy consumption in a dwelling due to renovation, retrofit, or improvement of equipment at a local scale. Modeling REC can be very useful for policy makers and householders. REC models depend on climate variations, thermal zone, building construction, neighborhoods, local population, life standards, region or nation. Our objective is to provide an up-to-date review of different modeling techniques used for modeling REC. Two main approaches are identified: top-down and bottom-up. Each method depends on different levels of input data information, different calculation or simulation techniques, and shows results with different applicability. A detailed review of each technique, focusing on the strengths, shortcomings, and purposes, is provided along with a review of the reported models.

\section{OVERVIEW OF MODELING METHODOLOGIES}

In this section, we intend to outline the methodologies and the available techniques for modeling residential sector, as this has already been given in detail elsewhere [5, 7-11]. Residential energy models strongly depend on input data to calculate or simulate energy consumption. The level of detail of the available input data can vary dramatically [11], resulting in the use of different modeling techniques which seek to take advantage of the available information. Modeling and control of the air temperature and humidity in greenhouses in order to reduce energy consumption and keep a suitable microclimate are discussed in [12]. Measures to control photovoltaic energy use and shading effect on energy consumption are developed in [13]. The measurements taken to reduce energy consumption in residential building should not affect thermal comfort conditions. Some authors have suggested and studied the effect of facade shading and green roofs in conserving thermal comfort with less consumed energy [14-16]. These different modeling techniques have different strengths, weaknesses, capabilities, and applicabilities. The input data necessary to build residential energy models include information on the physical characteristics, occupants and their appliances, historical data of energy consumption, climatic conditions, and macroeconomic indicators of the dwellings, depending on the modeling methodology to be used. The preliminary estimate of the total residential sector energy consumption is usually published by governments which compile gross energy values submitted by energy providers (Canada [11], USA [17], UK [18], and China [19]). These energy estimations give a good indication for energy consumption but may not be accurate as they do not take in account the onsite energy gain or generation. A more detailed source of energy consumption data, typically on a monthly basis for each dwelling, is the billing records of energy suppliers. However, with no additional housing information these energy consumption values are difficult to correlate due to the wide variety of dwellings and occupants.

Housing surveys are conducted to provide more detailed information about equipment energy consumption values. The target of these surveys is a sample of residential dwellings to determine building properties and occupant characteristics and appliances penetration levels (Canada [20], USA [21], and UK [22]). Usually, surveys aim to define the physical properties of the house such as geometry and thermal properties of the envelope, ownership of appliances, occupants and their use of appliances and preferred settings, and demographic characteristics. In addition, surveys may attempt to obtain the energy suppliers' billing data and alternative energy source information (e.g. unreported wood usage) to correlate the energy consumption of the house with its characteristics identified during the survey. This will permit the calibration through reconciliation of a model's predicted energy consumption with actual energy billing data. This level of information is superior to the previously mentioned energy supplier values, however it is limited due to collection difficulties and cost, and therefore it is imperative that the selected sample be highly representative of the population. Also, occupant descriptions of their appliance use are highly subjective and can be influenced by the season during which the survey takes place [20]. Some examples of surveys which have been condensed for the purpose of energy simulation are 
[21-23]. Estimated total sector energy, individual billing data, surveys, and sub-metering have been used to varying degrees in the development of residential energy consumption models. Deciding which information is used depends on availability and model's purpose. The purpose of models ranges widely and may be directed towards determining supply requirements, price and income elasticity, the energy consumption impacts of upgrades, or changes to behavioral patterns.

\section{RESIDENTIAL ENERGY USE MODELING METHODOLOGIES}

The complexity of residential energy use patterns and the dependence on data input level make modeling residential energy use potentially challenging. However, based on different capabilities, strengths, weaknesses, and the applicability of each modeling technique, matching input data with models that can best use them can produce satisfactory models. Generally speaking, techniques employed to model residential energy use can be classified into two categories, "top-down" and "bottom-up", and this terminology is referred to the hierarchal position of data inputs [5]. Top-down models are mostly uses at a macroscopic level, by governments building departments while bottom-up models are used at microscopic level by engineers (see [5] for details).

\section{A. Top-down Models}

The use and development of the top-down modeling approach proliferated with the energy crisis of the late 1970s. In an effort to understand consumer behavior with changing supply and pricing, broad econometric models were developed for national energy planning. These models require little detail of the actual consumption processes. The models treat the residential sector as an energy sink and regress or apply factors that affect consumption to determine trends. Most top-down models rely on similar statistical data and economic theory. As the housing stock in most regions is continuously undergoing improvement and increase, simply modeling the energy consumption solely as a function of economic variables is short termed. Authors in [24] initiated an annual housing energy model of the USA. Their model relied on econometric variables and included a component for growth/contraction of the housing stock. Their work was expanded and improved over the following years resulting in an econometric model which had both housing and technology components [25, 26]. The housing component evaluates the number of houses based on census data, housing attrition and new construction. The technology component increases or decreases the energy intensiveness of the appliances as a function of capital cost. The economic component evaluates changes in consumption based on expected behavioral changes and efficiency upgrades made to the technology component. Finally, market penetration is considered a function of income and demand/supply. The simulation model combines the changes in outputs of the components and estimates the energy consumption given historic energy consumption values. The authors felt their model was sensitive to major demographic, economic and technological factors, but recognized the need to continually update all assumed information to improve quality. Authors in [25] developed a similar model for New Zealand although it had a technological focus.

\section{B. Bottom-up Models}

The bottom-up approach was developed to identify the contribution of each end-user towards the aggregate energy consumption value of the residential stock. This refines the understanding of the details associated with the energy consumption. There are two distinct categories used in the bottom-up approach to evaluate the energy consumption of particular end-uses. The statistical models (SMs) utilize dwelling energy consumption values from a sample of houses and a variety of techniques to regress the relationships between the end-uses and the energy consumption. SM models can utilize macroeconomics, energy prices, income, and other regional or national indicators, thereby gaining the strengths of the top-down approach. The engineering models (EMs) category relies on information of the dwelling characteristics and end-uses themselves to calculate the energy consumption based on power ratings and use characteristics and/or heat transfer and thermodynamic principles. Consequently, the engineering technique has strengths such as the ability to model new technologies based solely on their traits. Once developed, the bottom-up models may be used to estimate the energy consumption of houses representative of the residential stock and then these results can be extrapolated to be representative of the regional or national residential sector.

\section{CONCLUSION}

Top-down models are used mostly for supplying analysis based on long-term projections of energy demand by taking in account the historical response. Bottom-up statistical models are used to identify the energy demand contribution of end-uses by introducing the behavioral aspects based on the data obtained from energy authorities and surveys. Bottom-up engineering techniques are used to explicitly calculate energy consumption of end-uses taking in account the detailed descriptions of a representative set of houses, and they have the capability of determining the impact of new technologies. Given today's energy considerations that include supply, efficient use, and effects of energy consumption to the promotion of conservation, efficiency, and technology implementation, all modeling approaches are useful. Top-down models are more useful in supply considerations because they are strongly weighted by historical energy consumption which makes their estimates of supply more accurate. Bottom-up statistical models can account for occupant behavior and use of major aggregates, leading to understand which of behaviors and end-uses cause more energy consumption. Lastly, bottomup engineering models may identify the impact of new technologies based on their characteristics and account for the wide degree of variety within the housing stock. To determine the impacts of such new developments requires a bottom-up model with more focus on efficiency and surveys on energy consumption generation at individual houses. In this fast technological development and implementation environment, the bottom-up techniques will likely provide much utility as policy and strategy development tools.

Although bottom-up building physics stock models are used to explicitly determine and quantify the impact of different combinations of technological measures on delivered energy use and $\mathrm{CO}_{2}$ emissions, and therefore represent an 
important tool for policymakers, there are some limitations associated with modeling. The most important shortcoming of all these models is their lack of transparency and quantification of inherent uncertainties. The lack of publicly available detailed data on the models inputs and outputs, as well as underlying algorithms renders any attempt to reproduce their outcomes problematic. In addition, the relative importance of input parameter variations on the predicted demand outputs needs to be quantified.

\section{REFERENCES}

[1] Energy Information Administration, International Energy Outlook 2016 With Projections to 2040, Technical Report Series, Vol. 484, EIA, 2016

[2] O. G. Santin, Actual energy consumption in dwellings: The effect of energy performance regulations and occupant behavior, IOS Press, 2010

[3] L. Lutzenhiser, "A question of control: Alternative patterns of room airconditioner use", Energy and Buildings, Vol. 18, No. 3-4, pp. 193-200, 1992

[4] H. Jeeninga, M. Uyterlinde, J. Uitzinger, Energieverbruik van energiezuinige woningen, ECN-C-01-072, ECN, 2001 (in Dutch)

[5] L. G. Swan, V. I. Ugursal, "Modeling of end-use energy consumption in the residential sector: A review of modeling techniques", Renewable and Sustainable Energy Reviews, Vol. 13, No. 8, pp. 1819-1835, 2009

[6] L. Itard, F. Meijer, Towards sustainable northern European housing stock: Figures, facts and future, IOS Press, 2008

[7] S. D. Tuladhar, M. Yuan, P. Bernstein, W. D. Montgomery, A. Smith, "A top-down bottom-up modeling approach to climate change policy analysis", Energy Economics, Vol. 31, pp. S223-S234, 2009

[8] C. Bohringer, T. F. Rutherford, "Combining bottom-up and top-down", Energy Economics, Vol. 30, No. 2, pp. 574-596, 2008

[9] C. Bohringer, T. F. Rutherford, "Integrated assessment of energy policies: Decomposing top-down and bottom-up", Journal of Economic Dynamics and Control, Vol. 33, No. 9, pp. 1648-1661, 2009

[10] N. Strachan, R. Kannan, "Hybrid modelling of long-term carbon reduction scenarios for the UK", Energy Economics, Vol. 30, No. 6, pp. 2947-2963, 2008

[11] N. Behidj, J. Bernier, S. Blais, D. Demers, S. Genest, C. Ramsum, K. Sassi, Energy use data handbook: 1990 and 1998 to 2004, Natural Resources Canada, 2006

[12] M. Jomaa, M. Abbes, F. Tadeo, A. Mami, "Greenhouse modeling, validation and climate control based on fuzzy logic", Engineering, Technology \& Applied Science Research, Vol. 9, No. 4, pp. 4405-4410, 2019

[13] A. S. Saidi, M. B. Slimene, M. A. Khlifi, "Transient stability analysis of photovoltaic system with experimental shading effects", Engineering, Technology \& Applied Science Research, Vol. 8, No. 6, pp. 3592-3597, 2018

[14] S. M. Wahba, B. A. Kamel, K. M. Nassar, A. S. Abdelsalam, "Effectiveness of green roofs and green walls on energy consumption and indoor comfort in arid climates", Civil Engineering Journal, Vol. 4, No. 10, pp. 2284-2295, 2018

[15] U. M. Burciaga, P. V. Saez, F. J. H. Ayon, "Strategies to reduce CO2 emissions in housing building by means of CDW", Emerging Science Journal, Vol. 3, No. 5, pp. 274-284, 2019

[16] S. Wahba, B. Kamil, K. Nassar, A. Abdelsalam, "Green envelop impact on reducing air temperature and enhancing outdoor thermal comfort in arid climates", Civil Engineering Journal, Vol. 5, No. 5, pp. 1124-1135, 2019

[17] Energy Information Administration, Annual energy review 2006 , DOE/EIA-0384(2006), EIA, 2006

[18] Department for Business Enterprise \& Regulatory Reform, Energy consumption in the United Kingdom, 2007

[19] National Bureau of Statistics of China, China statistical yearbook 2005, China Statistics Press, 2005
[20] Office of Energy Efficiency, 2003 survey of household energy use (SHEU)-detailed statistical report, Natural Resources Canada, 2006

[21] Energy Information Administration, Residential energy consumption survey, U.S. Energy Information Administration, 2001

[22] Department for Communities and Local Government. English house condition survey: technical report (2005 edition). West Yorkshire: Communities and Local Government Publication Centre, 2007

[23] International Energy Agency, Mapping the energy future: Energy modelling and climate change policy, International Energy Agency, 1998

[24] E. Hirst, W. Lin, J. Cope, "A residential energy use model sensitive to demographic, economic, and technological factors", Quarterly Review of Economics \& Business, Vol. 17, No. 2, pp. 7-22, 1977

[25] E. Hirst, "A model of residential energy use", Simulation, Vol. 30, No. 3, pp. 69-74, 1978

[26] D. L. Oneal, E. Hirst, "An energy use model of the residential sector”, IEEE Transactions on Systems, Man, and Cybernetics, Vol. SMC-10, pp. $749-755,1980$ 